\title{
TU/e EmonONEN

\section{Development and validation of a three-dimensional finite element model of the pelvic bone}

\section{Citation for published version (APA):}

Dalstra, M., Huiskes, H. W. J., \& Erning, van, L. (1995). Development and validation of a three-dimensional finite element model of the pelvic bone. Journal of Biomechanical Engineering : Transactions of the ASME, 117(3), 272-278. https://doi.org/10.1115/1.2794181

DOI:

10.1115/1.2794181

Document status and date:

Published: 01/01/1995

\section{Document Version:}

Publisher's PDF, also known as Version of Record (includes final page, issue and volume numbers)

\section{Please check the document version of this publication:}

- A submitted manuscript is the version of the article upon submission and before peer-review. There can be important differences between the submitted version and the official published version of record. People interested in the research are advised to contact the author for the final version of the publication, or visit the $\mathrm{DOI}$ to the publisher's website.

- The final author version and the galley proof are versions of the publication after peer review.

- The final published version features the final layout of the paper including the volume, issue and page numbers.

Link to publication

\section{General rights}

Copyright and moral rights for the publications made accessible in the public portal are retained by the authors and/or other copyright owners and it is a condition of accessing publications that users recognise and abide by the legal requirements associated with these rights.

- Users may download and print one copy of any publication from the public portal for the purpose of private study or research.

- You may not further distribute the material or use it for any profit-making activity or commercial gain

- You may freely distribute the URL identifying the publication in the public portal.

If the publication is distributed under the terms of Article 25fa of the Dutch Copyright Act, indicated by the "Taverne" license above, please follow below link for the End User Agreement:

www.tue.nl/taverne

Take down policy

If you believe that this document breaches copyright please contact us at:

openaccess@tue.nl

providing details and we will investigate your claim. 


\section{Development and Validation of a Three-Dimensional Finite \\ Element Model of the Pelvic Bone}

M. Dalstra

R. Huiskes

Biomechanics Section, Institute of Orthopaedics,

University of Nijmegen,

Nijmegen, The Netherlands

Member ASME

L. van Erning

Institute of Diagnostic Radiology. University Hospital Nijmegen St. Radboud Nijmegen, The Netherlands
Due to both its shape and its structural architecture, the mechanics of the pelvic bone are complex. In Finite Element (FE) models, these aspects have often been (over) simplified, sometimes leading to conclusions which did not bear out in reality. The purpose of this study was to develop a more realistic FE model of the pelvic bone. This not only implies that the model has to be three-dimensional, but also that the thickness of the cortical shell and the density distribution of the trabecular bone throughout the pelvic bone have to be incorporated in the model in a realistic way. For this purpose, quantitative measurements were performed on computer tomography scans of several pelvic bones, after which the measured quantities were allocated to each element of the mesh individually. To validate this $F E$ model, two fresh pelvic bones were fitted with strain gages and loaded in a testing machine. Stresses calculated from the strain data of this experiment were compared to the results of a simulation with the developed pelvic FE model.

\section{Introduction}

The pelvic bone forms the upper part of the hip, and therefore plays an important role in the load transfer across this joint. During normal walking, the hip joint force reaches values up to three or four times bodyweight. Also a number of powerful muscles are attached to the pelvic bone. Unlike long bones, which have to withstand similar loads and therefore have developed thick cortical shafts, the pelvic bone consists mainly of low-density trabecular bone, and is only covered by a thin cortical layer. In this, it resembles a so-called "sandwich" construction $[9,3]$, used in engineering to combine low weight and high strength. For the pelvic bone, this means that the bulk of the load is carried by and transferred through the cortical shell, while the trabecular bone acts as a spacer, keeping the shells from collapsing.

Having this complex geometry and structure, the basic mechanics of the pelvic bone are still not quite as well understood as, for example, that of the femur. In studying the mechanics of the pelvic bone, strain gage experiments $[9,17,13,5,20]$ and finite element analyses $[6,21,2,16,15,18,8,11,3,19$, $12]$ have been the two most frequently used methods, although photoelastic models [7, 23, 14] and thermo-elastic emission techniques are occasionally being used as well. Potentially, the Finite Element Method (FEM) offers the most possibilities, as the other methods are surface techniques, which can only measure and describe phenomena taking place on the outside of the bone.

However, the other methods normally use actual pelvic bones on which the measurements are performed, while for the FEM a computer model of the bone has to be constructed. The quality of FE results, therefore, is dependent on the quality of the model. The mechanics of the femur, for example, can very well be analyzed using 2-D models [22], but for the pelvic bone this is entirely different. The first pelvic FE models with spinoff in designing acetabular prostheses, were either 2-D [21, 2,

Contributed by the Bioengineering Division for publication in the JOURNAL of BIOMEChanical EngineERING. Manuscript received by the Bioengineering Division December 20, 1992; revised manuscript received August 18, 1994. Associate Technical Editor: B. Simon.
18] or axisymmetric semi 3-D [16, 8] approximations of the real geometry. From a mechanical point of view, though, neither of these two approaches can adequately describe the mechanical situation around the acetabulum and throughout the rest of the pelvic bone. A 2-D model can not account for the out-of-plane part of the acetabular wall and will therefore be too flexible. Vasu and co-workers found stresses exceeding 30 percent of the yield stress (appr. $120 \mathrm{MPa}$ ) and therefore they concluded that their 2-D model must overestimate the stresses [21]. With an axisymmetric model just the opposite occurs, for in this case it is inherently assumed that the acetabular wall is present around the full 360 degrees. The opening between the pubic and ischial bones (the incisura acetabuli), however, shows that in reality this is not the case. These models, therefore, overestimate the real stiffness. So did Pedersen and co-workers find stresses in the cortical shell due to a physiological value of the hip joint force to lie in the order of $0.5 \mathrm{MPa}$ [16], which is improbably low. This gap between stresses of $40 \mathrm{MPa}$ in a 2$\mathrm{D}$ model and $0.5 \mathrm{MPa}$ in an axisymmetric model suggest that by its shape and architecture, the pelvic bone is so typically three-dimensional by nature, that a FE analysis of the pelvic bone has to be done with a 3-D model. However, these models have negative aspects too. For a 3-D FE model of a complex structure like the pelvic bone to be accurate, many elements are required. This not only makes the computer analyses more time consuming and therefore more expensive, but also the pre- and postprocessing becomes much more cumbersome. In the last few years, however, increased computer capabilities have made 3-D models more accessible and because of this, the most recent pelvic FE studies have only made use of 3-D models [11, 3, $19,12]$. Allocation of the material properties to the elements of a pelvic mesh is a problem, as well. In most, if not all, studies of the mechanics of the pelvic bone by means of a 3-D FE model, homogeneously distributed Young's moduli of trabecular bone and a uniform thickness of the cortical shell were assumed. Because of its sandwich behavior, the load transfer across a pelvic bone will be relatively insensitive to changes in the material properties of the trabecular bone [3]. The thickness of the cortical layer, however, is directly coupled to its stiffness and load-transmitting capability and, therefore, it is to be ex- 

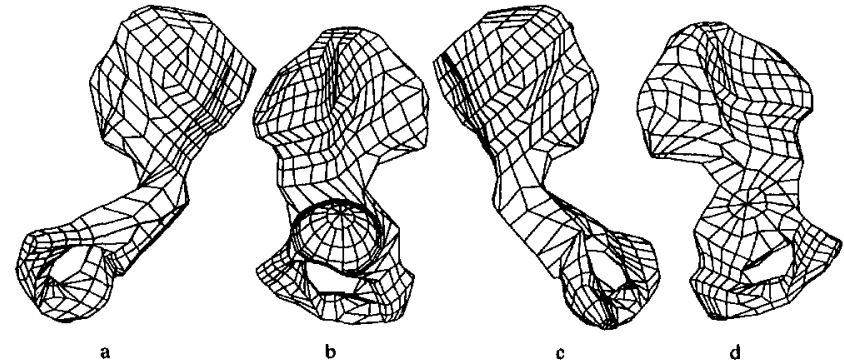

Fig. 1 The FE mesh of the left pelvic bone, seen lateral, (b) a posterior, (c) and a medial, (d) view

pected that variations in this parameter will certainly influence the overall load transfer mechanism of the pelvic bone.

The purpose of this study was to develop and validate a realistic 3-D finite element model of the pelvic bone. Quantitative computer tomography scanning of several pelvic bones, together with data from an earlier study on the mechanical properties of pelvic trabecular bone [4], was used to supply data for the FE mesh concerning the distribution of the density of the trabecular bone (and thus its Young's modulus) and the thickness of the cortical shell. This FE model was then verified by simulating a loading experiment with fresh pelvic bones fitted with strain gages, and comparing the numerical and experimental output. As a control, a 3-D FE model with homogeneous material properties and a cortical shell with uniform thickness was also included in this comparison.

\section{Methods and Materials}

Finite Element Mesh. A left pelvic bone of a 87 year old male donor was submerged in polyester resin. Fixed to the bone was a set of three small brass bars, which had been added for orientation purposes; originating in the center of the acetabulum, the first was aligned with the pubic bone, the second with the ischial bone and the third with the iliac bone. After hardening of the resin, the pelvic bone was sectioned by cutting $6 \mathrm{~mm}$ slices perpendicular to the brass bars. This meant that the pubic, the ischial and the iliac bones were sectioned perpendicular to their 'longitudinal' axes. The contours of the sectioned bones were then digitized and, because the relative positions of the brass bars were known relative to one another, the spatial position of the contours could be reconstructed. This reconstruction was done in a Cartesian coordinate system defined by a plane over the rim of the acetabulum ( $x y$-plane, the $x$-axis bisecting the angle between the ischial and pubic bones) and the $z$-axis as the normal to this plane, pointing into the acetabulum. The area within a contour was divided into 4-node elements and using a computer program, the respective elements in the subsequent contours were then connected to each other, forming the basic mesh consisting of 8-node parametric brick elements. Some additional adjustments to the nodes and elements were necessary to make the sub-meshes of the iliac, pubic and ischial bone fit to one another at the acetabulum. Several views of the basic mesh are shown in Fig 1.

The brick elements in the basic mesh only represent the trabecular and the subchondral bone. Given the dimensions of these elements, the cortical shell is so thin, that it could not be modeled by brick elements, since the thickness to length ratio (aspect ratio) of the elements would have been too small. In analogy with other $3-D$ pelvic studies $[15,11,19]$, membrane elements were chosen to represent the cortical layer, as these elements are compatible with brick elements. Keeping in mind the role of the cortical shell in the pelvic sandwich construction, it is not to be expected that the cortical bone will be heavily loaded perpendicular to the shell, and therefore membrane elements, which can only be submitted to in-plane loading, will be sufficient to describe the mechanical situation within the cortical shell. With another computer program, all the faces of the brick elements on the outer surface of the basic mesh were covered by 4 -node membrane elements. Finally, the contralateral pelvic bone was added by mirroring the mesh in the sagittal plane. This final mesh consisted of 2602 elements with a total of 1862 nodes.

Quantitative Computer Tomography, Both pelvic bones of a 89 year old male donor were available. After being stripped of soft tissues, the bones were stored at $-18^{\circ} \mathrm{C}$ until scanning and subsequent testing. The bones were scanned with a CTscanner (Siemens, SOMATOM DR3) operating in dual-energy mode ( 85 and $125 \mathrm{kVp}$ ). According to the coordinate system mentioned above, scans were taken parallel to the $y z$-plane. The slice thickness of a scan was $4 \mathrm{~mm}$ and the distance between two consecutive scans was $4 \mathrm{~mm}$ as well. Given the dimension of the bones, this resulted in a total of 57 scans per bone. A calibration phantom was included in the scans in order to be able to relate the $\mathrm{X}$-ray absorption values for bone to a $\mathrm{Ca}$ equivalent density, a quantity expressing the amount of hydroxyapatite per volume [10]. Postprocessing the CT-data, socalled water-equivalent and calcium-equivalent images were reconstructed, of which only the latter were used for further evaluation. Via a network, the digital images were transferred to a PC, equipped with an image-analysis system (TIM, Difa Measuring Systems, Breda, the Netherlands). This system was basically used to obtain two quantities. The first was the thickness of the cortical shell, which was directly measured as the distance between two points marked by the user on the outside and inside of the cortical shell. Owing to the calcium-equivalent images, the cortical shell was clearly distinguishable with a sharp contour and therefore it posed no problem defining two points on both sides of the shell. The second quantity was the Ca-equivalent density of the trabecular and subchondral bone, which was more elaborate to measure. First, an area-of-interest had to be defined by the user and in this area the grey values of all pixels were averaged. Then, an area on both sides of the calibration phantom had to be marked as well. By interpolating the average grey value of the area-of-interest between the grey values (with known Ca-equivalents) of the areas on the phantom, the Ca-equivalent density in the area-of-interest was found.

These measurements were performed twice. First, they were done to examine the differences between the left and the right bone. For this purpose, only the maximal cortical thickness and the average Ca-equivalent density for the entire trabecular bone area from each scan were recorded and compared to the respective values of the contralateral scan. After this, the measurements were repeated in order to allocate the quantities to the elements of the FE mesh. To do this as accurately as possible, mappings of cross-sections through the $\mathrm{FE}$ mesh were made in order to be able to transpose the exact locations of the individual elements to an area-of-interest in the scans. Figure 2 shows an example of a scan through the lower half of the acetabulum, with the accompanying cross-section through the FE mesh. At each location of an element, the thickness (for the membrane elements) or the Ca-equivalent density (for the brick elements) were measured and allocated to this element. If a particular element appeared in more than one scan, its values of the density or thickness were averaged after the measurements in all scans had been completed.

Mechanical Testing. The two bones, which had been used for the QCT measurements, were also used in the strain gauge experiment. Each bone was fitted with eight 90 deg rosette strain gages (FRA-1-11; Tokyo Sokki Kenkyujo Co., Japan). The locations of the gages were chosen both on the lateral and medial cortical shell (Fig. 3). The bones were placed upside down with their iliac crests submerged in a bed of acrylic cement. The anatomical position of the bones relative to one an- 


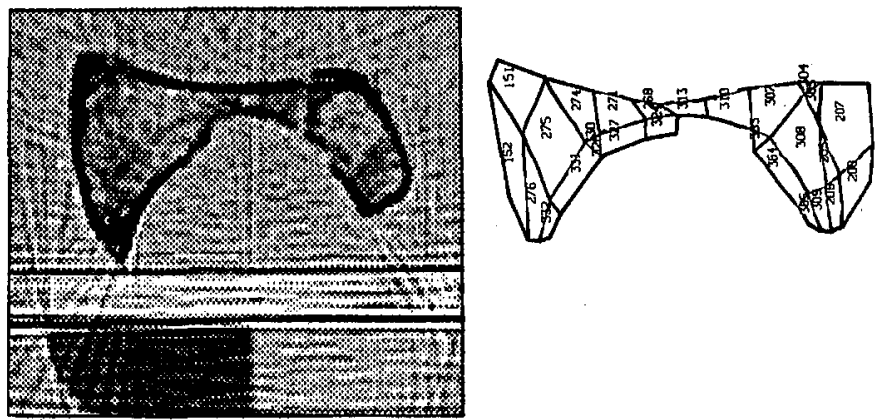

Fig. 2 A CT-scan from the lower acetabular region with the accompanying section of the FE mesh

other was maintained and contact at the pubic symphyses was restored.

After hardening of the cement, the bones were placed in an MTS-based testing machine (DSTS Engineering \& Electronics, Zoetermeer, the Netherlands). The position of the bones was such that the direction of a vertical load, applied through a femur-shaped lever arm, would correspond to that of the hip joint force during one-legged stance (Fig 4). This position had been found by applying a coordinate transformation to telemetry data by Bergmann and co-workers [1] from their femur-based coordinate system to the present acetabulum-based coordinate system. Each bone was loaded separately by applying forces of $150,300,450$, and $600 \mathrm{~N}$. At each load increment, the strains in the gages were recorded and stored in a PC. From these data, the principal strains and stresses, the von Mises stresses and the maximal shear stresses were calculated afterwards. For the calculations of stresses, a Young's modulus of $17 \mathrm{GPa}$ and a Poisson's ratio of 0.3 were assumed for the cortical bone.

Finite Element Analyses. The mesh described above was used in two FE analyses. The first model had material properties according from the results of the CT-measurements. The Caequivalent density and the cortical thickness measured at the respective locations of each brick and membrane element were used as input for these elements. The relationship between $\mathrm{Ca}$ equivalent density ( $\left.\rho_{\text {Ca-eq }}\right)$, apparent density $\left(\rho_{\text {app }}\right)$ and Young's modulus (E) of both trabecular and subchondral bone was based on two relations which had been established in an earlier study: $\rho_{\text {Ca-eq }}=0.626 \rho_{\text {app }}$ and $\mathrm{E}=2017.3 \rho_{\text {app }}^{2.46}[4]$. This study also showed that pelvic trabecular bone can be assumed as isotropic and that its Poisson's ratio is close to 0.2. Furthermore, based on current values reported in literature, the Young's modulus and Poisson's ratio of cortical bone were assumed to be $17 \mathrm{GPa}$ and 0.3 , respectively. For the second FE model, the same mesh was used, but in this case material properties were assumed to be homogeneous. Young's modulus and Poisson's ratio for trabecular, subchondral and cortical bone were taken to be 70 $\mathrm{MPa}$ and $0.2,2 \mathrm{GPa}$ and 0.3 , and $17 \mathrm{GPa}$ and 0.3 , respectively. In accordance with other $3-D$ pelvic models $[6,15]$, a cortical thickness of $1 \mathrm{~mm}$ was used. As the sub-mesh of the right side pelvic bone merely had an auxiliary function, in both models its elements were given the same material properties as used for the homogeneous model.

Both the "realistic" and the homogeneous model were supported by keeping the nodes on the superior iliac crest fixed, which corresponded to the boundary conditions of the experimental set-up. To simulate the exact loading conditions from the experiment, a part of the femur-shaped lever arm had to be included in the model, which, in correspondence to the experiment, was only allowed to move vertically. The actual loading was applied by a vertically directed point load of $600 \mathrm{~N}$ at the back of the lever arm. Figure 4 shows a lateral and a frontal view of the experimental set-up of the FE model. Contact between the ball-shaped head and the acetabular surface was modelled by 60 gap elements, thus ensuring that only compressive forces could be transferred onto the acetabulum. In the analyses the so-called "assumed strain" option for the 8-node brick elements was flagged. This option improves the response of linear elements to bending by modifying their interpolation functions such that shear strain variation can be better represented [24]. The analyses were performed using the MARC/MENTAT FEM and pre- and postprocessing codes (MARC Analysis Corporation, Palo Alto, CA, USA) running on the EX-60 mainframe computer (Hitachi Data Systems, Japan) of the University of Nijmegen.

\section{Results}

Dual Energy Quantitative Computer Tomography. The results of the CT-measurements showed a very close resemblance between the left and right bone. In Fig. 5, it can be seen that both the maximal cortical thickness and the average Caequivalent density per scan have a high degree of similarity between left and right. Apart from the close resemblance of the curves, it also shows that the highest values for the cortical thickness (just over $3 \mathrm{~mm}$ ) are found at the level of the superior
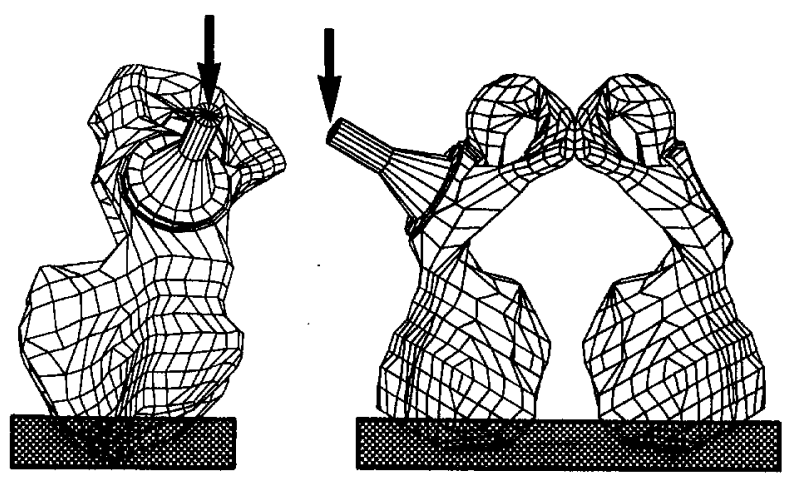

Fig. 4 FE simulation of the loading experiment (lateral and frontal view) 


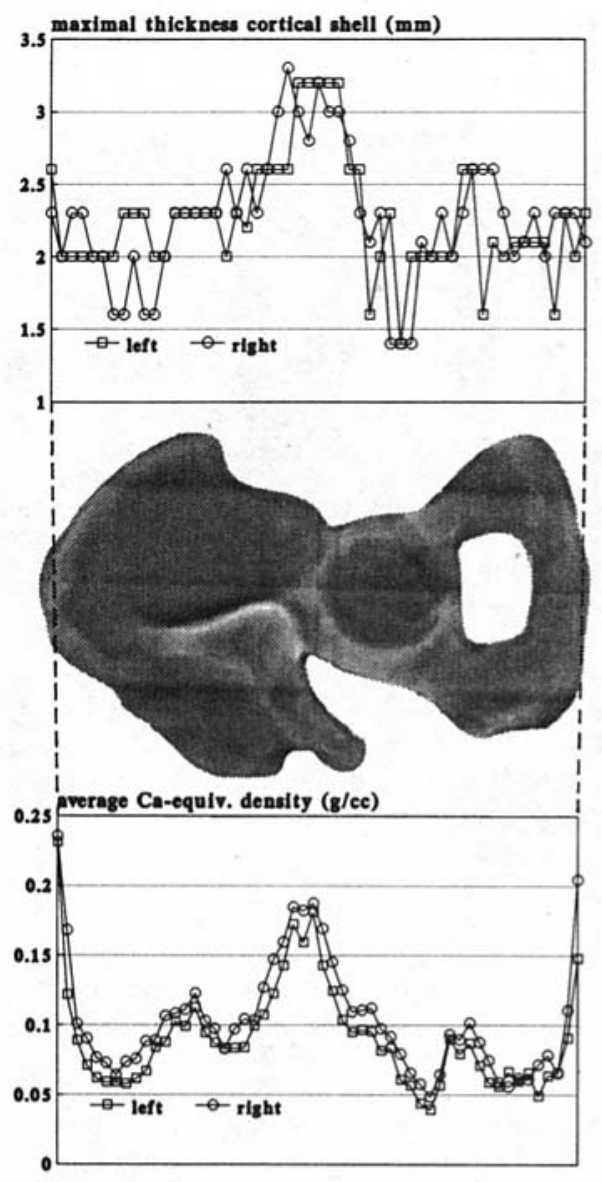

Fig. 5 Values of the maximal cortical thickness (top) and the average Ca-equivalent density (bottom) for the left and the right bone

acetabular rim. Here, also the average trabecular density is highest. The increase of the Ca-equivalent density at both ends of the curves is an anomaly and is caused by "cortical interference"; in the first and last two scans, the trabecular bone could not be identified separately from the cortical shell, thus yielding the higher absorption values.

Having this good agreement in material properties between the left and the right bone, only the left pelvic bone was used for the CT-measurements to allocate the material properties to the individual elements. In Fig. 6, the distribution of both the thickness of the cortical bone and the Young's modulus (calculated directly from the Ca-equivalent density) of the trabecular bone are shown. The values are already transposed onto their



Fig. 7 Von Mises stresses at the eight strain gages for both left and right pelvic bone as a function of the load applied in the setup

respective elements in the FE mesh. Cortical thicknesses of 2 $\mathrm{mm}$ and up are found at the incisura ischiadaca major region extending up the iliac bone. Also the top of the iliac bone has a relatively thick cortex. At the articular surfaces of the sacroiliac joint and the pubic symphysis, cortical thickness is less than $1 \mathrm{~mm}$. For the trabecular Young's modulus the average value lies around $40 \mathrm{MPa}$. Areas with relatively high densities are found around the acetabulum extending to the sacro-iliac joint, where values of around $100 \mathrm{MPa}$ are found. However, the highest value was only $186 \mathrm{MPa}$. It should be noted that the Young's moduli for the subchondral bone are not included in Fig. 6. For this type of bone, the Young's modulus was found to be one order of magnitude higher than for the trabecular bone, with values ranging between 132 and 2,155 MPa.

Mechanical 'Testing. The applied loads had been relatively low to ensure that the strains and stresses measured at the strain gage locations were linearly related to the magnitude of that load (Fig. 7). When correlating, for instance, the von Mises stresses at each gage location to the magnitude of the applied load, even the lowest value for $R^{2}$ was still 0.954 (gage 7 of the left bone; Fig. 3). The highest stresses occurred at location 8 , the medial cortical shell right underneath the acetabular dome. Also the locations 1,2 (the superior acetabular rim) and 5 (the pubic bone) showed relatively high stresses. The least stressed area was location 7, lying in the incisura ischiadaca major region. As mentioned above, in this region the cortical shell had been found to be relatively thick and therefore the local resistance against deformation is higher.

In Fig. 8, the range between the maximal and minimal principal stresses is given for each strain gage. This shows that at some gages, the similarity between left and right is less consistent as Fig. 7 suggests. At gage 3 of the left bone, for instance, only tensile stresses occur, while at the same location on the
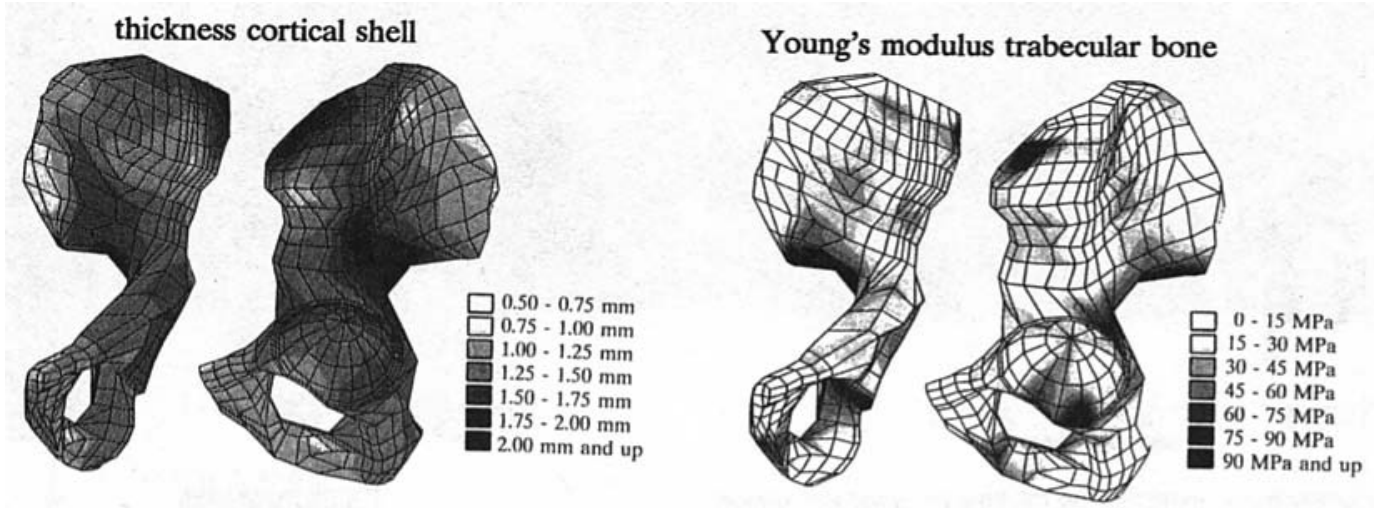

Fig. 6 Distributions of the thickness of the cortical shell and the Young's modulus of the underlying trabecular bone, as measured from the CTscans and transposed onto the FE mesh (frontal and lateral view) 


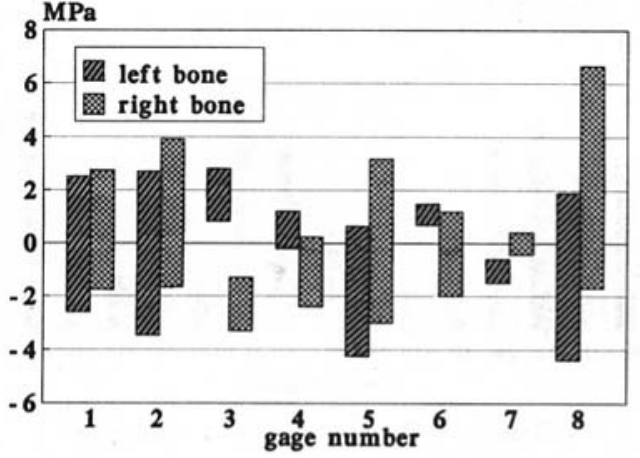

Fig. 8 Ranges between the maximal and minimal principal stresses at the eight strain gage locations found in the experiment for both left and right pelvic bones at a load of $600 \mathrm{~N}$

right bone only compressive stresses are found. However, the von Mises stresses at both gages are almost the same, as can be seen in Fig. 7.

Finite Element Analyses. Given the differences between the stresses in the left and right bone in the experiment, the numerical and experimental results compared well. For both models, the tensile principal stresses at locations 1 to 4 were more or less directed circumferentially to the acetabulum. At location 5, the compressive principal stress was directed in the longitudinal direction of the pubic bone, while at locations 6 to 8 , the compressive principal stress was parallel to the direction of the load. This was in accordance with the respective principal directions, found in the experiment. Also the magnitude of the stresses corresponded well to the experimental values. Figure 9 compares the range of the principal stresses at the locations of the strain gages for the experiment, the "realistic" FE model and the homogeneous FE model. The minimal principal stresses predicted by the realistic FE model agree very well with the experimental findings. At locations $1,2,5$, and 6, the maximal principal stresses are somewhat lower than the experimental results. The stresses predicted by the homogeneous model are generally higher than the ones predicted by the realistic model. This becomes clear in Fig. 10, which shows the von Mises stresses at the strain gage locations. At locations 2, 3, and 7, the homogeneous model predicts stresses, which exceed both the realistic and the experimental results. These increases are caused by increased compressive stresses at these locations, as can be seen in Fig. 9. The differences in the stresses at the strain gage locations between the two FE models indicate that

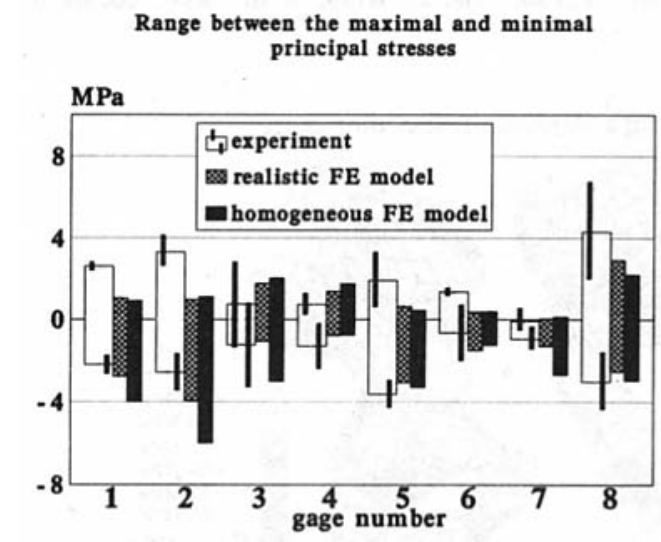

Fig. 9 Ranges between the maximal and minimal principal stresses at the eight strain gage locations found in the experiment (averaged for the left and right bone; the bars denote the standard deviations) and for both the realistic and the homogeneous model at a load of $600 \mathrm{~N}$

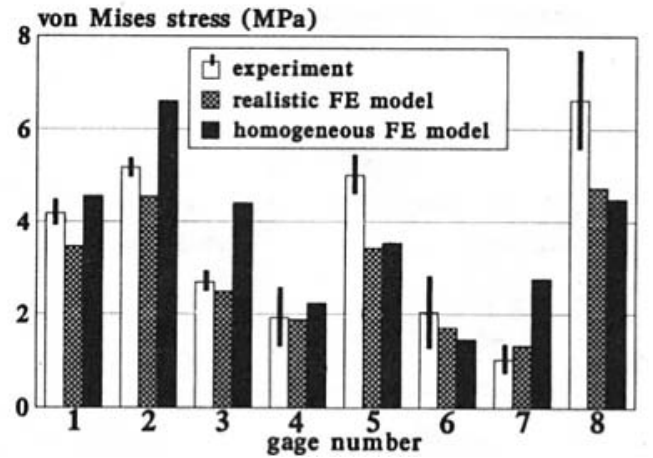

Fig. 10 The von Mises stresses found in the experiment (averaged for the left and right bone; the bars denote the standard deviations) and both the realistic and the homogeneous model at a load of $600 \mathrm{~N}$

the overall load transfer between the two models may differ as well. This is illustrated in Fig. 11, where the distributions of the von Mises stresses in the cortical shell are given for both the realistic model and the homogeneous model. For both models, the overall load transfer is governed by the hip joint force, of which a major part is transferred from the acetabulum to the area of support at the iliac crest and a minor part is transferred onto the contralateral pelvic bone through the pubic bone. The highest stresses, therefore, are found at the superior acetabular rim, extending through the central part of the iliac bone toward the iliac crest and also at the pubic bone (Fig. 11). The stresses in this "central column" of the iliac bone are predominantly compressive and are directed parallel to the line of action of the applied load. In this particular loading mode, with no muscles present, the ischial bone and the anterior and posterior parts of the iliac bone remain virtually unloaded. The stress intensity is generally higher for the homogeneous model; especially in the areas of primary load transfer, like the superior acetabular rim and the incisura ischiadaca major region, where the homogeneous model is too flexible due to the underestimation of the cortical thickness.

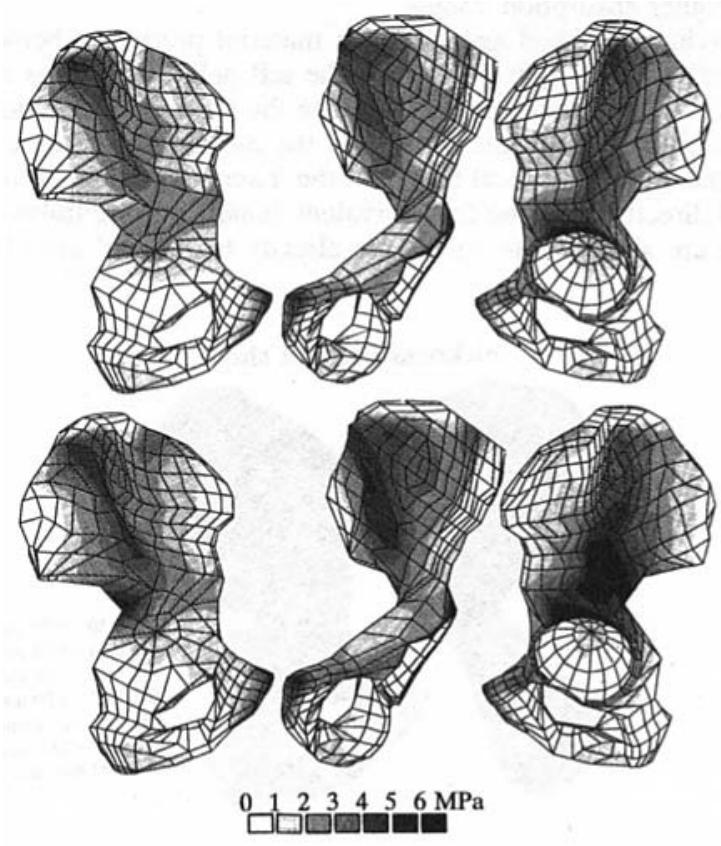

Fig. 11 Distribution of the von Mises stresses in the cortical shell of the realistic model (top) and the homogeneous model (bottom) 


\section{Discussion}

From a mechanical point of view, the pelvic bone is a complex structure. Not only due to its three-dimensional character, but also by the distribution of different types of bone. The bulk of its material is low-density trabecular bone, which is covered by a thin cortical shell. The thickness of this layer is not uniformly distributed over the bone and is adjusted to the load transfer across the pelvic bone. To take this into account when analyzing pelvic mechanics by means of the finite element method, a 3-D model of the pelvic bone, featuring homogeneously distributed material properties and a cortical shell with a uniform thickness, may not be sufficient. We have tried to develop a physiological pelvic FE model in which the material properties of the trabecular bone and the thickness of the cortical shell were based on quantitative measurements from dual-energy CT-scans of an actual pelvic bone. It might be argued that the values obtained from only one bone of one individual ( $\delta$, $89 \mathrm{yr}$ ) will limit the applicability of the model. However, comparative measurements performed on the contralateral bone of the same donor showed that the distributions of trabecular density and cortical thickness between the left and the right bone were virtually symmetrical (Fig. 5). Furthermore, the densities measured were compared to values found for a series of eight other pelvic bones of both male and female donors of the same age group [4], and were found to be in the same range. It can therefore be assumed that the measured values of this particular bone were neither exceptionally low nor high. As one of the future uses for this FE model will be to assess acetabular prostheses, the allocation of material properties of bone from elderly people may not be considered to be a problem.

The Young's moduli for trabecular bone calculated from the measured Ca-equivalent densities varied between 1 and 186 $\mathrm{MPa}$, which is in accordance with earlier observations [21]. This shows that pelvic trabecular bone is at least an order of magnitude less stiff as trabecular bone of femoral or tibial origin, for which values of $1500 \mathrm{MPa}$ are not exceptional. Yet, these higher values have often been used in pelvic FE studies $[6,15,18,16,8]$. The Young's modulus of the subchondral bone layer in the acetabulum ranged between 132 and 2,155 $\mathrm{MPa}$. The thickness of the cortical shell varied between 0.7 and $3.2 \mathrm{~mm}$ (Fig. 6). The highest values were found in the regions of primary load transfer (the superolateral part of the acetabular rim and the incisura ischiadaca major area leading to the sacroiliac joint). The articulating surfaces of the cortical shell at the sacro-iliac joint and pubic symphysis displayed thicknesses below $1 \mathrm{~mm}$. From these measurements it appears that 3-D models with a uniform cortical thickness of $1 \mathrm{~mm}[6,15]$ may be somewhat unrealistic. Goel and co-workers found stresses of nearly $60 \mathrm{MPa}$ (for a bodyweight of $70 \mathrm{~kg}$ ) in the cortical shell. Oonishi and co-workers, on the other hand, reported very low stresses; from their results it appears that the von Mises stresses in the cortex are well below $1 \mathrm{MPa}$. However, they apparently made a mistake in calculating the magnitude of the load from kgf to $N$ (instead of multiplying by 9.8 , they seem to have divided by 9.8 , which would mean that their results are almost a factor 100 too small!). If this is the case, their results become comparable again to those of Goel and co-workers. Stresses of this magnitude are indeed much too high to occur in cortical bone during normal walking and would in reality lead to rapid fatigue failure. It must, therefore, be concluded that both models are too flexible.

To verify our FE model, the bones which had been used for the CT-measurements were also used for strain gage measurements in a loading machine. In this testing procedure, the only load applied to the pelvic bones was a force directed into the acetabulum, simulating the hip joint force at one-legged stance. Because no muscle forces were simulated and due to the unnatural fixation of the pelvic bones at the top of the iliac crest, instead of at the articulating surface of the sacro-iliac joint area, this setup cannot be considered to be physiologically realistic. However, this was not the intention in the first place, as its sole purpose was to obtain data which could be directly compared to the results from the analyses with the FE model.

It is difficult to compare the experimental stresses with values from the literature, because in the various reported pelvic strain gage studies, different aspects of pelvic mechanics were examined. Jacob and co-workers did not use actual bones for their experiment, but epoxy models [9]. Furthermore, they included muscle forces. Petty and co-workers did use actual bones, but they were only interested in the strains in a particular region at the medial cortex [17], where in our case no strain gage was present. Finlay and co-workers reported on stresses in the cortical shell of a normal pelvic bone [5]. However, when calculating stresses from the strains, they assumed a Young's modulus of $6.2 \mathrm{GPa}$ for cortical bone, which seems rather low. The magnitude and direction of the load in their study also differ from the present case. Although the stresses are of the same order of magnitude as our findings, their results are somewhat lower due to the lower cortical Young's modulus. Ries and coworkers looked at the strains in the pelvic cortical shell as a function of the size of the head of a hemiarthroplasty [20]. The results of this study can neither be compared to the present ones, as they give no absolute values of these strains. Miles and McNamee looked at the load transfer in the pelvic bone being affected by the position of the axis of rotation [14]. However, like Ries and co-workers, they neither gave absolute values of the strains they measured.

When comparing the strain gage results with the FE results, one should re:alize that strain gage measurements supply only local data, which is in fact an average of the real strains occurring underneath the gage. The outcome of a FE analysis provides a continuous field of strains or stresses, and if sharp gradients in these quantities are present, it will be virtually impossible to find a perfect match between experiment and FE model. Beside the stress/strain gradients, another reason for experimental and numerical mismatch might be the use of the membrane elements for the cortical shell. For the 'realistic' model, relatively high values for the thickness of the membrane elements had to be allocated at some locations. It was unknown, how this would affect the performance of these membrane elements. Therefore, benchtesting of these elements with increasing thicknesses was done and this showed that an element with a thickness of $50 \%$ of its length overestimated the actual results by only 10 percent. Therefore, this can be considered a minor effect. Finally, there was a difference in the size of the head of the femur-shaped lever arm used in the experiment and in the FE model. Based on the sizes of the acetabula of the bones used in the experiment, the actual head had a diameter of 45 $\mathrm{mm}$. The larger acetabulum of the bone on which the FE mesh had been based, required an FE head with a diameter of 62 $\mathrm{mm}$. This difference will certainly affect the stresses within the acetabulum and its close surroundings. Most strain gages were, however, located in the periphery. Even with these discrepencies, we believe that the stresses from the FE models showed a reasonable agreement to the experimental ones. As to be expected, the results from the 'realistic' model were better than the homogeneous model, although the results from the latter were not that far off, either. However, the homogeneous model overestimated the stresses by an average 30 percent, particularly in the areas of primary load transfer, where the realistic model had a thicker cortical shell to compensate for the higher loads.

It can therefore be concluded that the presently developed FE model has the basic ability to describe the stress and strain distributions in the pelvic bone realistically. For comparative studies, a less elaborate model with homogeneously distributed material properties may be used. However, if absolute values of mechanical quantities are to be examined, it will certainly pay off to use a more detailed model. 


\section{References}

1 Bergmann, G., Graichen, F., and Rohlmann, A. "Instrumentation of a Hip Joint Prosthesis," Implantable Telemetry in Orthopaedics, Bergmann, Graichen, Rohlmann, eds., Freie Universität Berlin, 1990, pp. 35-63.

2 Carter, D. R., Vasu, R., and Harris, W. H. "Stress distributions in the acetabular region II: effects of cement thickness and metal backing of the tota hip acetabular component," J. Biomech., Vol. 15, 1982, pp. 165-170.

3 Dalstra, M., and Huiskes, R. "The Pelvic Bone as a Sandwich Construction; a Three Dimensional Finite Element Study," Proc. ESB, Vol. 7, 1990, p. B32.

4 Dalstra, M., Huiskes, R., Odgaard, A., van Erning, L. "Mechanical and Textural Properties of Pelvic Trabecular Bone," J. Biomech., Vol. 26, 1993, pp $523-535$.

5 Finlay, J. B., Bourne, R. B., Landsberg, P. D., Andreae, P. "Pelvic Stresses in vitro-I. Malsizing of Endoprostheses," J. Biomech., Vol. 19, 1986, pp. 703714.

6 Goel, V. K., Valliappan, S., and Svensson, N. L. "Stresses in the Normal Pelvis,"' Comput. Biol. Med., Vol, 8, 1978, pp. 91-104.

7 Holm, N. J. "The Development of a Two-Dimensional Stress-Optical Model of the Os Coxae," Acta Orthop. Scand., Vol. 52, 1981, pp. 135-143.

8 Huiskes, R. "Finite Element Analysis of Acetabular Reconstruction," Acta Orthop. Scand., Vol. 58, 1987, pp. 620-625.

9 Jacob, H. A. C., Huggler, A. H., Dietschi, C., Schreiber, A. "Mechanical Function of Subchondral Bone as Experimentally Determined on the Acetabulum of the Human Pelvis," J. Biomech., Vol. 9, 1976, pp. 625-627.

10 Kalender, W. A., Suess, C. "A Calibration Phantom for Quantitative Computed Tomography," Med. Phys., Vol. 14, 1987, pp. 863-866.

11 Koeneman, J. B., Hansen, T. M., and Beres, K. "Three Dimensional Finite Element Analysis of the Hip Joint," ORS Trans., Vol. 14, 1989, p. 223.

12 Landjerit, B., Jacquard-Simon, N., Thourot, M., Massin, P. H. "Physiological Loadings on Human Pelvis: A Comparison Between Numerical and Experimental Simulations," Proc. ESB, Vol. 8, 1992, p. 195.

13 Lionberger, D., Walker, P. S., Granholm, J. "Effects of Prosthetic Acetabular Replacement on Strains in the Pelvis," J. Orthop. Res., Vol. 3, 1985, pp. $372-379$.
14 Miles, A. W., and McNamee; P. B. "Strain gauge and photoelastic evaluation of the load transfer in the pelvis in total hip replacement: the effect of the position of the axis of rotation," Proc. Instn. Mech. Engrs., Vol. 203, 1989, pp. $103-107$.

15 Oonishi, H., Isha, H., and Hasegawa, T. "Mechanical analysis of the human pelvis and its application to the articular hip joint-by means of the three dimensional finite element method," J. Biomech., Vol. 16, 1983, pp. 427-444.

16 Pedersen, D. R., Crowninshield, R. D., Brand, R. A., and Johnston, R. C. "An Axisymmetric Model of Acetabular Components in Total Hip Arthroplasty," J. Biomech., Vol. 15, 1982, pp. 305-315.

17 Petty, W., Miller, G. J., and Piotrowski, G. "In Vitro Evaluation of the Effect of Acetabular Prosthesis Implantation on Human Cadaver Pelves,' Bull. Pros. Res., Vol. 17, 1980, pp. 80-89.

18 Rapperport, D. J., Carter, D. R., and Schurman, D. J. "Contact Finite Element Stress Analysis of the Hip Joint," J. Orthop. Res., Vol. 3, 1985, pp $435-446$.

19 Renaudin, F., Lavaste, F, Skalli, W., Pecheux, C., and Scmitt, V. "A 3D Finite Element Model of Pelvis in Side Impact," Proc. ESB, Vol. 8, 1992, p. 194.

20 Ries, M., Pugh, J., Au J. C., Gurtowski, J., and Dee, R. "Cortical Pelvic Strains With Varying Size Hemiarthroplasty In Vitro," J. Biomech., Vol. 22, 1989, pp. $775-780$.

21 Vasu, R., Carter, D. R., and Harris, W. H. "Stress distributions in the acetabular region-I. before and after total joint replacement," J. Biomech., Vol. 15, 1982, pp. 155-164.

22 Verdonschot, N., Huiskes, R. "FEM Analyses of Hip Prostheses: Validity of the 2-D Side-Plate Model and the Effects of Torsion," Proc. ESB, Vol. 7, 1990 , p. A20.

23 Yoshioka, Y., and Shiba, R. "A Study of the Stress Analysis of the Pelvis by Means of the Three-Dimensional Photoelastic Experiments," J. Jap. Orthop. Ass., Vol. 55, 1981, pp. 63-76.

24 Zienkiewicz, O. C. The Finite Element Method, 3rd ed., McGraw-Hill, London, 1977, pp. 272-276. 